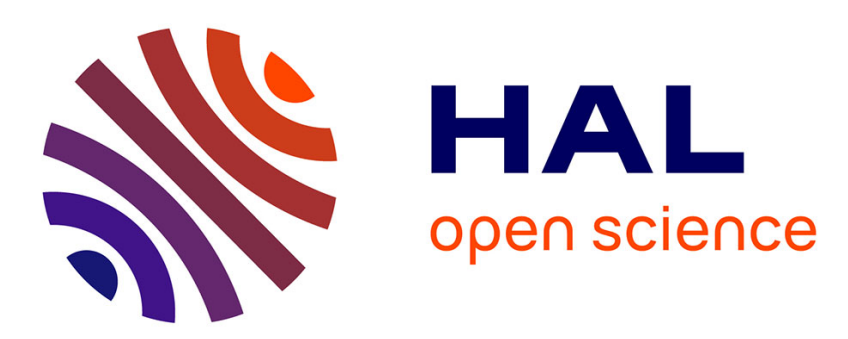

\title{
A new method to characterize chemically and topographically nanopatterned surfaces
}

\author{
A. Charrier, T.J. Porri, C.J. Murphy, P.F. Nealey
}

\section{To cite this version:}

A. Charrier, T.J. Porri, C.J. Murphy, P.F. Nealey. A new method to characterize chemically and topographically nanopatterned surfaces. Journal of Biotechnology, 2006, 126 (2), pp.196-204. 10.1016/j.jbiotec.2006.04.036 . hal-00122750

\section{HAL Id: hal-00122750 \\ https://hal.science/hal-00122750}

Submitted on 24 Apr 2020

HAL is a multi-disciplinary open access archive for the deposit and dissemination of scientific research documents, whether they are published or not. The documents may come from teaching and research institutions in France or abroad, or from public or private research centers.
L'archive ouverte pluridisciplinaire HAL, est destinée au dépôt et à la diffusion de documents scientifiques de niveau recherche, publiés ou non, émanant des établissements d'enseignement et de recherche français ou étrangers, des laboratoires publics ou privés. 


\title{
A new method to characterize chemically and topographically nanopatterned surfaces
}

\author{
Anne Charrier ${ }^{\mathrm{a}, \mathrm{b}, *}$, Teresa J. Porri ${ }^{\mathrm{c}}$, Christopher J. Murphy ${ }^{\mathrm{d}}$, Paul F. Nealey ${ }^{\mathrm{a}}$ \\ a Department of Chemical Engineering, University of Wisconsin, Madison, WI 53706, USA \\ ${ }^{\mathrm{b}}$ CRMCN-CNRS, Campus de Luminy, Case 913, 13288 Marseille Cedex 9, France \\ ${ }^{\mathrm{c}}$ Department of Materials Science and Engineering, University of Wisconsin, Madison, WI 53706, USA \\ ${ }^{\mathrm{d}}$ Department of Surgical Sciences, School of Veterinary Medicine, University of Wisconsin, Madison, WI 53706, USA
}

\begin{abstract}
Surface chemistry of topographically patterned grooved samples with ridges of $150 \mathrm{~nm}$ width, adsorbed with self-assembled monolayers (SAMs) of alkanethiols on gold, have been characterized by near edge X-ray absorption fine structure (NEXAFS) spectroscopy. Analysis reveals that NEXAFS may discriminate between different chemistries adsorbed to the tops, sidewalls and grooves of the patterns.
\end{abstract}

(c) 2006 Elsevier B.V. All rights reserved.

Keywords: NEXAFS; Biomimetic material; Thiol; Surface characterization; Protein adsorption

\section{Introduction}

With the development of biotechnologies, an increasing number of studies have been run on the fabrication and characterization of biomimetic surfaces. Such surfaces are made of inorganic material functionalized by organic molecules, playing the role of linker between organic and inorganic media. These molecules are usually self-assembled monolayers (SAMs) tethered by a specific ending group. These surfaces, which can be chemically (Endler et al., 2003;

\footnotetext{
* Corresponding author.

E-mail address: charrier@crmcn.univ-mrs.fr (A. Charrier).
}

Lopez et al., 1993; Arnold et al., 2004), topographically (Den Braber et al., 1998; Flemming et al., 1999; Karuri et al., 2004; Foley et al., 2005; Teixeira et al., 2003), and chemically and topographically (Britland et al., 1996; Mrksich et al., 1996) nanopatterned are critical to the field of tissue engineering for example. Previous work done by this group has shown that nanoscale topography is a biologically relevant stimulus by showing changes in adhesion (Karuri et al., 2004), differentiation (Foley et al., 2005), orientation, and alignment (Teixeira et al., 2003) of cells to chemically uniform, topographically patterned surfaces consisting of grooves and ridges with feature sizes ranging from $70 \mathrm{~nm}$ to $2 \mu \mathrm{m}$. In addition, materials displaying 
chemical surface patterning demonstrate that nanoscale chemical patterning is also a relevant cellular stimulus (Endler et al., 2003; Lopez et al., 1993; Arnold et al., 2004; Koo et al., 2002). The use of self-assembled monolayers, in particular, allows for chemical surface modification strategies to be readily undertaken (Prime and Whitesides, 1991).

It is important that these chemically and topographically patterned substrates are well characterized to fully explore the mechanisms of cell-substrate interactions. Substrates topographically patterned at the nanometer scale can readily be imaged by techniques such as a scanning electron micrograph (SEM) and an atomic force microscope (AFM), while flat nanoscale chemical patterns can be imaged by near-field scanning optical microscopy (NSOM) (Betzig and Trautman, 1992) or by the application of antibody-coated gold beads, which can later be viewed using SEM (Polak and Varndell, 1984). However, these methods are insufficient to characterize chemically and topographically nanopatterned surfaces. In this paper we describe for the first time a method that probes the structure of a chemically and topographically patterned substrate using near edge X-ray absorption fine structure (NEXAFS).

\section{Materials and methods}

\subsection{Samples patterning and selective chemical functionalization}

Topographically patterned samples were fabricated using X-ray lithography through a mask, as has been described in previous papers (Cerrina, 1997; Khan et al., 2001). Samples examined using SEM were found to have the following dimensions: pitch $=400 \mathrm{~nm}$, groove $=150 \mathrm{~nm}$ and depth $=280 \mathrm{~nm}$. Silicon wafers were coated with $10 \mathrm{~nm}$ of Ti, then $20 \mathrm{~nm}$ of Au by evaporation. Although this coating is not perfect on the surface, the $\mathrm{Ti}$ and $\mathrm{Au}$ are present everywhere, on the tops, sides and grooves as can be seen on Fig. 1.

Chemically and topographically patterned substrates were fabricated using the microcontact printing technique as described in Fig. 1. Briefly, a flat PDMS stamp is made by crosslinking Sylgard 184 on an unpatterned silicon wafer silanized with $\mathrm{CF}_{3}\left(\mathrm{CF}_{2}\right)_{5}\left(\mathrm{CH}_{2}\right)_{2} \mathrm{SiCl}_{3}$. The cured flat PDMS stamp is swabbed with a $2 \mathrm{mM}$ ethanolic solution of hexadecanethiol (HDT) (Sigma-Aldrich) (Kumar and Whitesides, 1993). This stamp is dried under nitrogen and pressed onto the surface. After the stamp is removed, the flat gold surface is immersed for $6 \mathrm{~h}$ in a $2 \mathrm{mM}$ ethanolic solution of 11-mercaptoundec-11-yl penta (ethylene glycol) (EG5) (The EG5 was synthesized in the lab following the procedure indicated by Pale-Grodemange et al. (1991). Chemically uniform surfaces are made by immersion in one of the solutions described above. In the first case where the sample is chemically patterned, we have tested whether the $\mathrm{EG}_{5}$ interchanged the HDT from the top of the patterns as it is suggested by anterior work by Biebuyck and Whitesides (1993) (Hähner et al., 1992). To do so, we adsorbed fluorescent fibronectin (Sigma-Aldrich) on the sample. After the HDT and PEG5 functionalization, the sample is rinsed three times $10 \mathrm{~min}$ with DI water, then three times $10 \mathrm{~min}$ in DPBS (BioWhitaker, Walkersville, MD). The sample is then left $1 \mathrm{~h}$ in a $10^{-3} \%$ fibronectin solution before being rinsed three times $10 \mathrm{~min}$ in DPBS and finally three times $10 \mathrm{~min}$ in DI water. The sample is blow dried with nitrogen. As the PEG $_{5}$ prevents the adsorption of proteins, the fibronectin should adsorb selectively on the tops of the patterns. The use of fluorescent fibronectin allows the detection of the protein with a fluorescent microscope. If the $\mathrm{PEG}_{5}$ was substituting the HDT, no protein should be adsorb on the sample. The Fig. 2 shows the result of such an experiment. Photos (a) and (c) have been taken on two different samples without and with proteins, respectively, using a white light to illuminate the sample while photos (b) and (d) have been taken on, respectively, the same samples but with a light at $520 \mathrm{~nm}$ (excitation at $488 \mathrm{~nm}$ ). On (a) and (c) we clearly see the patterns but there is no apparent difference between the photos that would indicate the presence of protein or not on the surfaces. In contrast, when using a light at $520 \mathrm{~nm}$, i.e. to probe the fluorescence of the protein, the photo (b) appears completely dark, as expected by the absence of proteins on the surfaces. This photo also indicates that the patterns cannot be seen at this wavelength. On photo (d), we clearly recover the patterns indicating first the selective adsorption of the proteins on tops of the patterns, and second that the $\mathrm{EG}_{5}$ has not substituted the HDT. In the case where this substitution had occurred no fluorescence would be observed. 

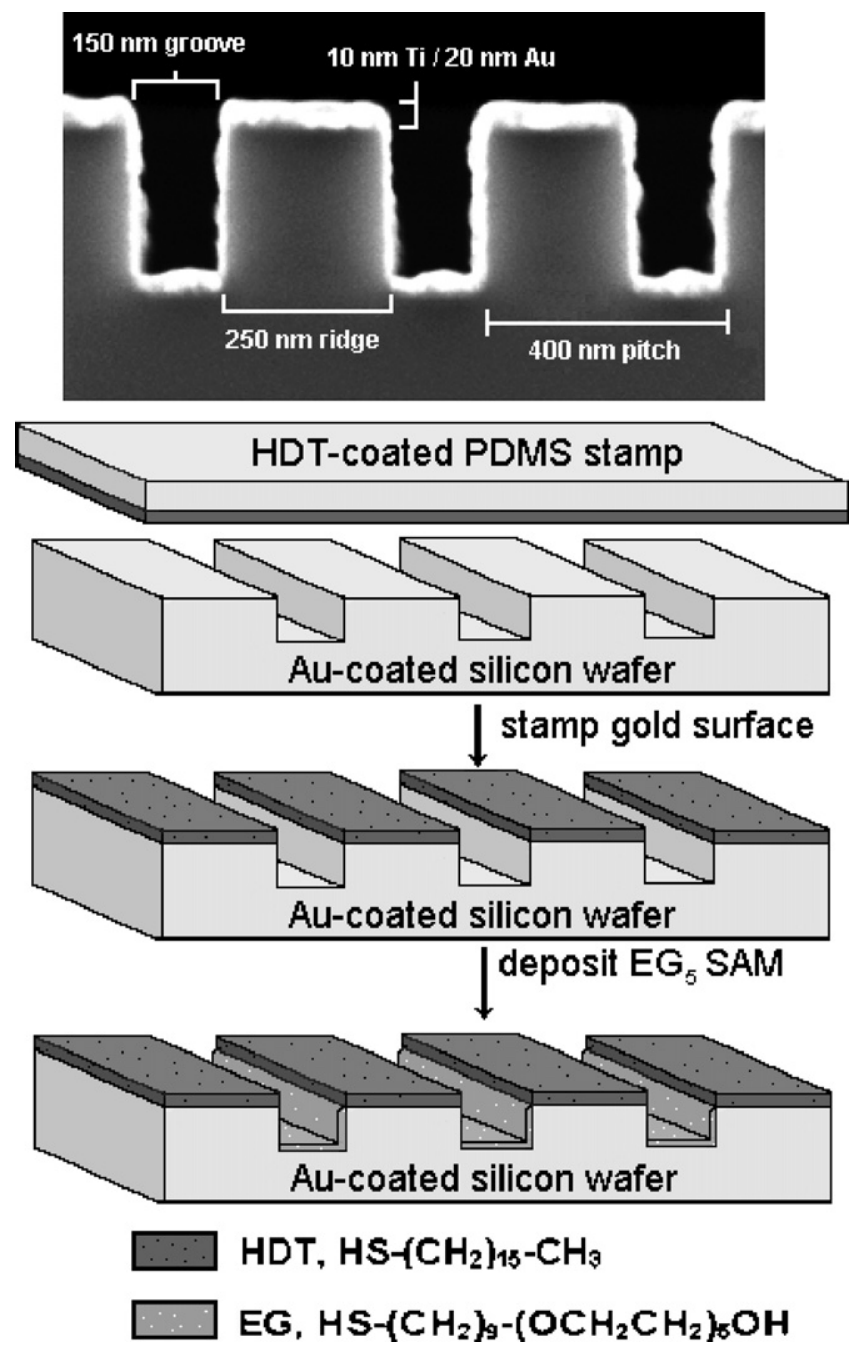

Fig. 1. Fabrication of topographically and chemically patterned $\mathrm{Si}$ wafers. Topographically patterned samples with a pitch of $400 \mathrm{~nm}$, a groove width of $150 \mathrm{~nm}$ and a depth of $280 \mathrm{~nm}$ are obtained with X-ray lithography subsequently coated with $10 \mathrm{~nm}$ Ti and $20 \mathrm{~nm}$ Au (shown in SEM cross-section). The chemical functionalization is obtained by application of a flat PDMS stamp coated with HDT to the silicon wafer patterned resulting in the coating of the tops of the pattern. $\mathrm{EG}_{5}$ is then adsorbed to the sidewalls and bottom of the pattern by immersion in ethanolic $\mathrm{EG}_{5}$ solution.

\subsection{NEXAFS experiments}

Carbon-edge NEXAFS spectra were taken at the Synchrotron Radiation Center of Madison, Wisconsin, on the Hermon beam line (port 33). Spectra were taken in total yield mode, with a resolution better than $0.2 \mathrm{eV}$. The base pressure in the chamber was lower than $10^{-10}$ Torr and all measurements were performed at room temperature. Spectra were recorded by rotating the sample around an axis perpendicular to the photon beam such that the angle of incidence of photons varies from $0^{\circ}$ (normal incidence, electric field ( $E$-vector) parallel to the surface) to $60^{\circ}$ (grazing incidence, $E$-vector nearly perpendicular to the surface) with respect to the sample surface normal. The light was at least $90 \%$ linearly polarized. Spectra were normalized to a clean gold reference signal evaporated on silicon to remove the transmission function of the optics and to a mesh 

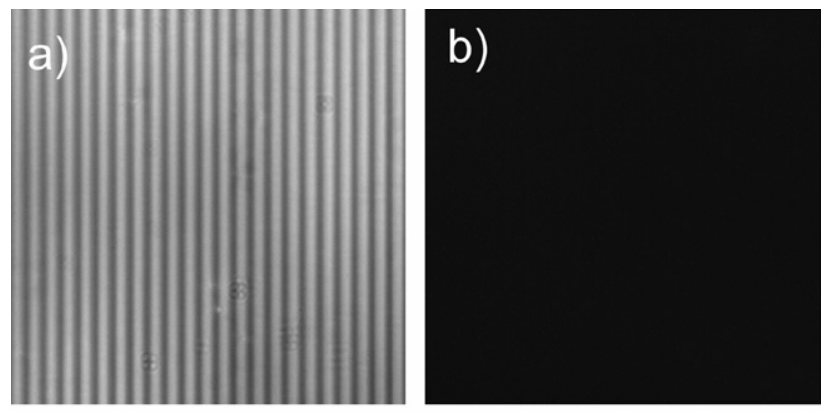

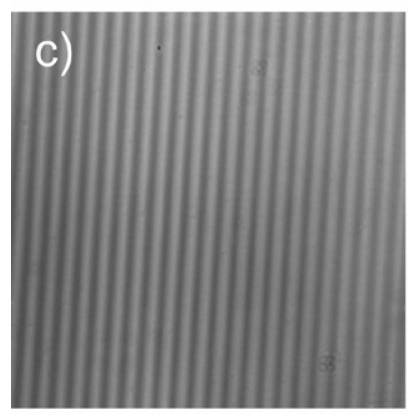

White Light

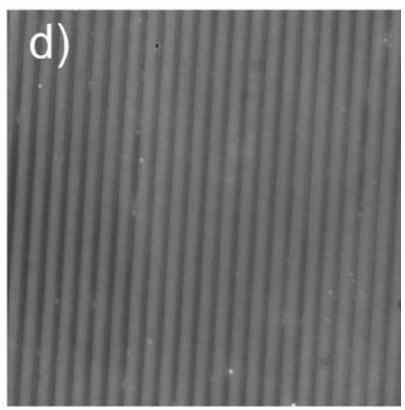

FITC Light

Fig. 2. Photos of chemically and topographically nanopatterned surfaces taken with a fluorescent optical microscope. HDT has been transferred from a PDMS stamp to the tops of the patterns while PEG $_{5}$ has been subsequently adsorbed on the sidewalls and grooves. Photos (a and c) have been taken on two different samples without and with proteins, respectively, using a white light to illuminate the samples while photos (b and d) have been taken on, respectively, the same samples but with a light at $520 \mathrm{~nm}$ (excitation at $488 \mathrm{~nm}$ ) to probe the fluorescence.

signal measured simultaneously to remove beam fluctuations. We also ensure that the surface patterning is oriented such that the patterns are oriented parallel to the axis of rotation, resulting in the change of illumination showed in Fig. 3(a). When this is not the case (i.e., the patterns are arrayed perpendicular to the axis of rotation), the tops and grooves are illuminated at all angles, and the spectra are identical to those of a flat surface (data not shown).

\section{Results and discussion}

\subsection{The method}

The method proposed in this paper exploits the properties of the NEXAFS technique to characterize the chemistry of nanostructured surfaces. NEXAFS probes molecular orbitals by the excitation of a core level electron into an unoccupied molecular orbital. Three main properties of NEXAFS are used here: first,
X-ray absorption spectra gives a signature of the specific chemical bonding environment. Second, the Xray absorption signal is proportional to the number of atomic bonds illuminated by the beam, which means we can directly correlate the effective illuminated area (Fig. 3(a and b)) to the resulting spectra. Finally, X-ray spectra are polarization ( $E$-vector) dependent. The $\mathrm{C}_{1 \mathrm{~s}}$ edge has been probed here for both HDT and $\mathrm{EG}_{5}$ in the energy range between 280 and $320 \mathrm{eV}$. We propose that by using the angular dependence of the NEXAFS signal to obtain the chemical "signature" of ordered layers of molecules adsorbed to flat surfaces, we will be able to calculate model spectra for patterned samples. A comparison of this rebuilt spectra with those experimentally obtained will give us information as to the structure and orientation of the thiols on patterned samples.

The model spectra are based on the following assumptions: for a given angle $\theta$ on a topographically patterned surface, there will be some areas illuminated by the beam, while other regions are cast into 

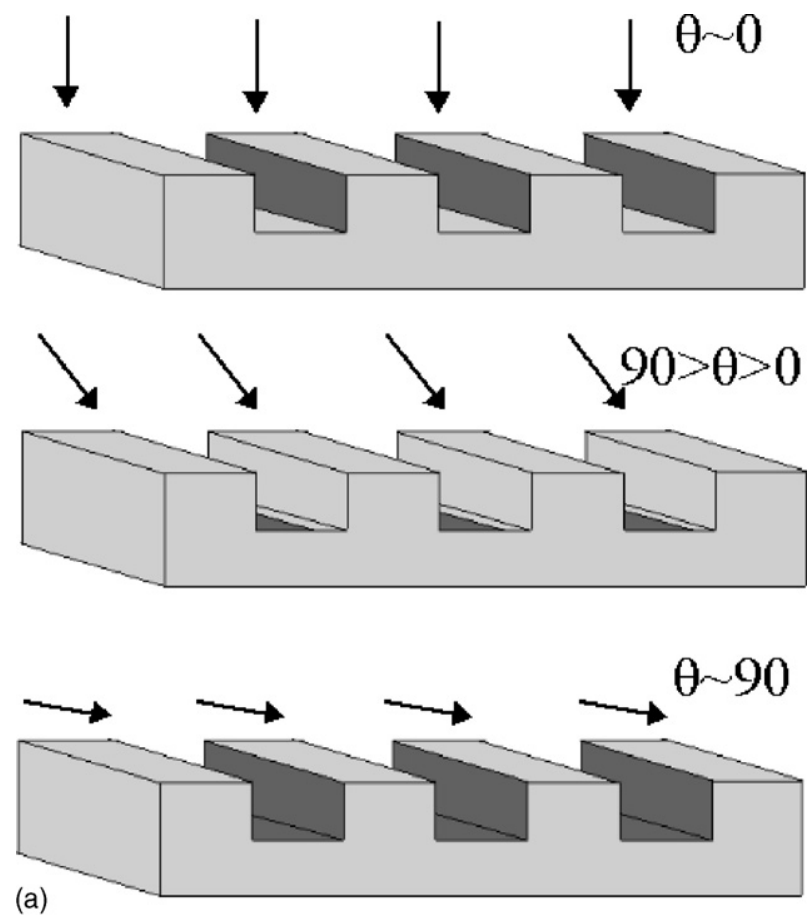

(a)

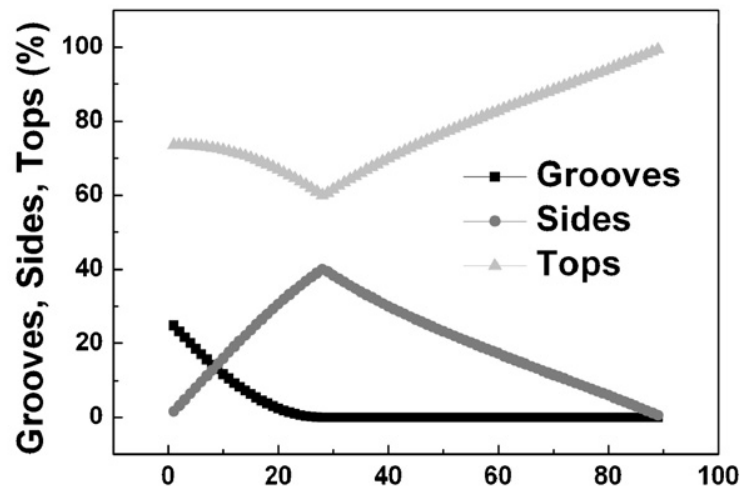

(b) Photon angle of incidence (deg)

Fig. 3. (a) Representation of relative regions of illumination at various incident beam angles. At normal beam incidence, the tops and bottoms only are illuminated. At intermediate angles, the top remains illuminated, while varying percentages of the grooves and sidewalls are shadowed. At glancing angles where $\theta$ approaches $90^{\circ}$, the tops alone are illuminated. (b) Effective illuminated areas of sidewalls, grooves and tops with respect to the photon angle of incidence, given as a percentage of the total illuminated area, as calculated for a substrate with the dimensions described.

shadow (Fig. 3(a)). The illuminated tops and grooves of the patterned sample will be described by a spectrum taken on a flat sample with the same angle of incidence $\theta$ and the sidewalls by a spectrum taken on the flat sample with an angle of $(\pi / 2)-\theta$. By combining these values we arrive at a final spectrum that takes all surfaces into account. This assumption is possible due to the azimuthal disorder of the molecules adsorbed to multicrystalline gold (Hähner et al., 1992). The formula used to reconstruct the spectra is indicated in Eq. (1), where $S_{\mathrm{p}}$ represents the rebuilt spectrum, $S_{\mathrm{F}}$ the flat spectrum and $x_{1}$ and $x_{2}$ the percentage of 
illuminated sidewalls and grooves, respectively. These last are obtained by the convolution of the effective illuminated area by the number of photons illuminating this area. The sidewalls contribution is given by $x_{1}=$ Groove $^{2} \times \cos (\theta) / \tan (\theta)$ and the groove contribution by $x_{2}=(\text { Groove-Depth } \times \tan (\theta))^{2} \times \cos (\theta)$. The tops are given by (Pitch-Groove) $)^{2} \times \cos (\theta)$. The results are shown in Fig. 3(b) for the patterned sample characteristics indicated previously.

$$
\begin{aligned}
S_{\mathrm{p}}(\theta)= & \underbrace{\left(1-x_{1}-x_{2}\right) S_{\mathrm{F}}(\theta)}_{\text {Tops }}+\underbrace{x_{1} S_{\mathrm{F}}(\pi / 2-\theta)}_{\text {Sidewalls }} \\
& +\underbrace{x_{2} S_{\mathrm{F}}(\theta)}_{\text {Grooves }}
\end{aligned}
$$

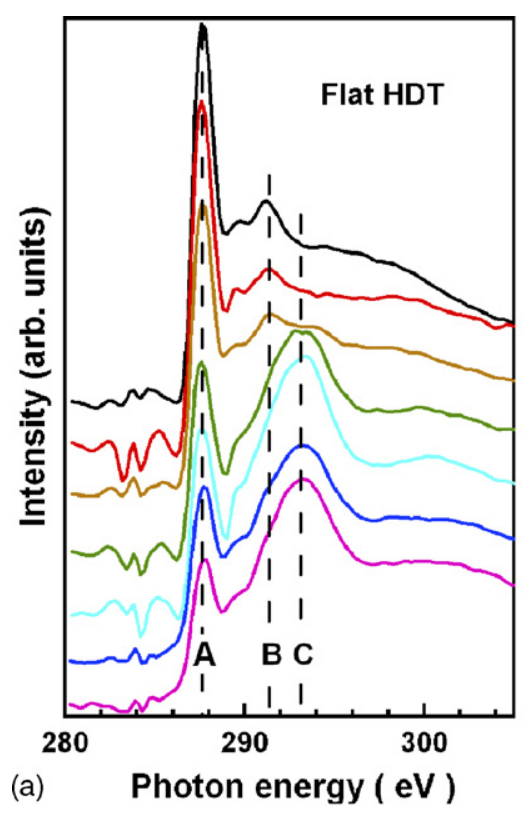

To rebuild spectra from chemically and topographically patterned substrates, we used spectra obtained on flat chemically uniform surfaces of HDT and $\mathrm{EG}_{5}$, respectively.

\subsection{Flat surfaces of HDT and PEG5}

The spectra for flat HDT and $\mathrm{EG}_{5}$ are shown in Fig. 4( $a$ and $b)$. The $E_{5}$ spectra are consistent with that of Zwahlen et al. (2003) (Biebuyck and Whitesides, 1993). HDT and PEG $_{5}$ are two very close hydrocarbon chains which differentiate from each other by their ending part. NEXAFS measurements have been realized on flat surfaces dipped in each of these two. For

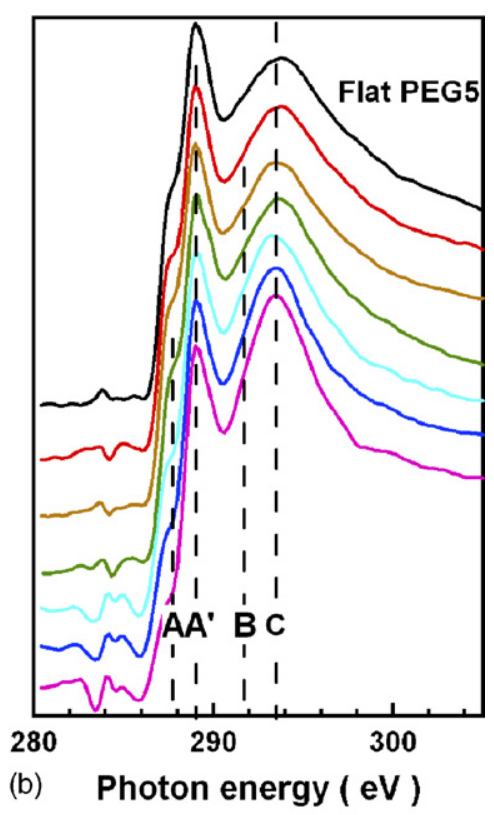

(b) Photon energy ( eV )

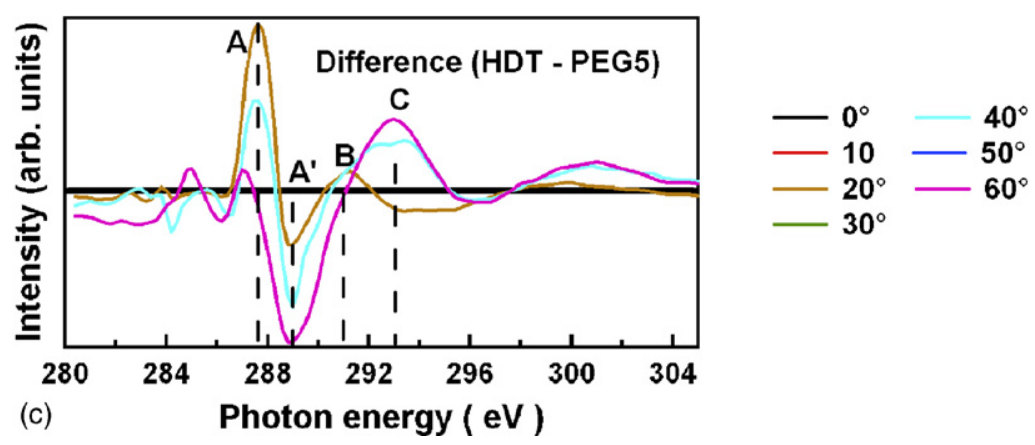

Fig. 4. NEXAFS spectra of HDT and $\mathrm{EG}_{5}$ on flat gold surfaces at various incident beam angles. (a) HDT on flat gold; (b) EG 5 on flat gold; (c) HDT spectrum subtracted from $\mathrm{EG}_{5}$ show significant variation between the two spectra. 
HDT, the spectra show the presence of two components at $287.7 \mathrm{eV}$ (A) and $293.2 \mathrm{eV}$ (C). These two peaks have a very strong angular dependence which indicates an average preferred orientation of the molecules on the surface as previously reported (Zwahlen et al., 2003). These peaks have been attributed to the $\mathrm{C}-\mathrm{H}$ and $\mathrm{C}-\mathrm{C} \sigma^{*}$ orbitals, respectively, associated with the $\mathrm{CH}_{2}-\mathrm{C}$ group in the alkane chain. In addition to these two strong peaks, measurements obtained on the $\mathrm{PEG}_{5}$ sample show the presence of an extra peak located at $289.2 \mathrm{eV}\left(\mathrm{A}^{\prime}\right)$. We have attributed this peak to the $\mathrm{C}-\mathrm{H}$ molecular orbital in the $\mathrm{CH}_{2}-\mathrm{O}$ group in $\mathrm{PEG}_{5}$ molecules. The two $\mathrm{C}-\mathrm{H}$ molecular orbitals (A and $\mathrm{A}^{\prime}$ ) are slightly shifted due to a different molecular environment. For both types of molecules, the peak A presents a high angular dependence. Its intensity, very high at $0^{\circ}$ decreases as the angle of incidence of the beam increases. The same observation can be done for the peak $\mathrm{C}$, but this time, the intensity of the peak increases with the angle of incidence of the beam. We should notice however that the angular dependence of the PEG5's peak C is lower than the HDT's. The peak $\mathrm{A}^{\prime}$ also presents a very small angular dependence.
The peak B present in both cases does not present any angular dependence. The difference between these two chemicals adsorbed on a gold surface is emphasized in Fig. 4(c) where three spectra obtained on the two surfaces at 0,20 and $40^{\circ}$ have been subtracted. The results show a very strong difference that indicates that NEXAFS is sensitive enough to discriminate between these two kinds of chemical species. Spectra from Fig. 4( $\mathrm{a}$ and $\mathrm{b}$ ) will be considered as a signature for each angle of incidence of photons for the two chemicals and will be used to rebuild the spectra on patterned samples.

\subsection{Topographically and chemically patterned surfaces of HDT and HDT/PEG 5}

In the following, two kinds of samples have been prepared. The first kind is patterned, and HDT is adsorbed everywhere on the sample (HDT sample). The second kind is also patterned, but this time HDT is only adsorbed to the tops while $\mathrm{PEG}_{5}$ is adsorbed to the grooves and ridges (HDT/PEG sample). NEXAFS spectra obtained on the first kind of samples are shown

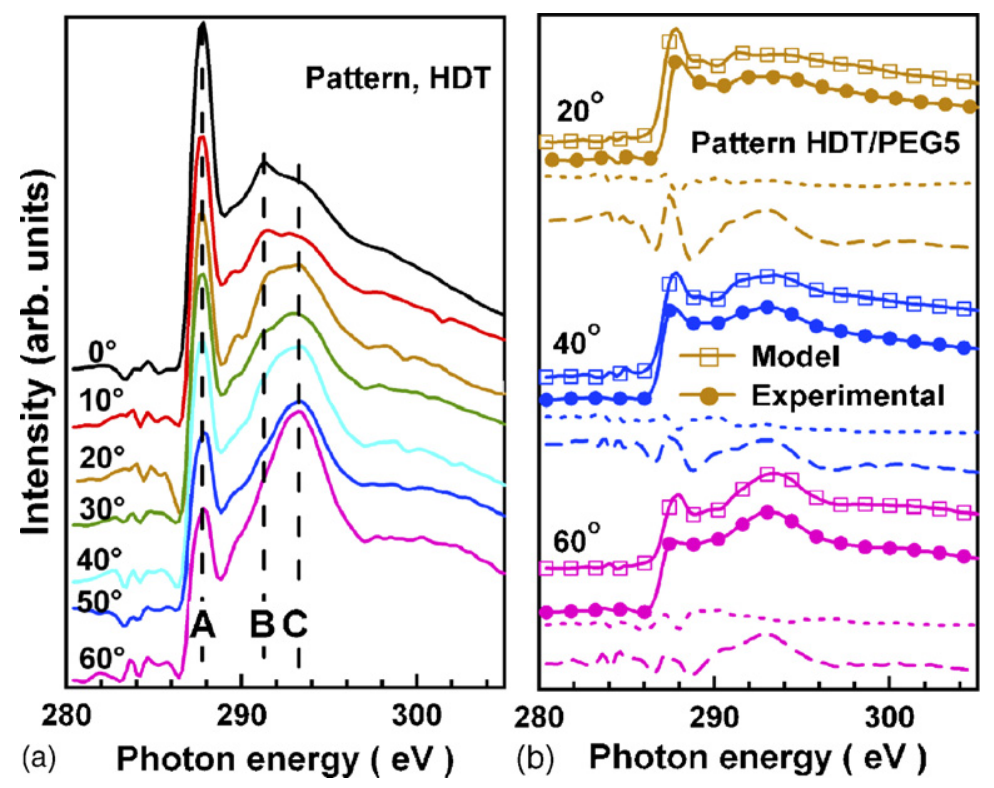

Fig. 5. (a) NEXAFS spectra of HDT obtained on topographically patterned samples. (b) Experimental (full circles) and model (empty squares) spectra for a HDT/PEG topographically and chemically patterned sample. The subtraction between these two spectra (dotted line) shows that the peak shapes are well predicted by the model. The subtraction between experimental spectra obtained on HDT topographically patterned samples and modeled spectra for HDT/PEG topographically and chemically patterned samples (dashed line) indicate that the method is sensitive to the chemistry even in the grooves and sidewalls of the patterns. 
in Fig. 5(a). The peaks A and $C$ have the same behavior than in the case of the flat sample (Fig. 4(a)), but their angular dependence is lower. This decrease is due to a lost of the global molecular orientation induced by the orientation of the molecules adsorbed on the sidewalls of the patterns. In the second set of measurements, NEXAFS spectra were obtained on the HDT/PEG samples. The model (triangles) and experimental (circles) spectra, respectively, modeled and measured at 20, 40 and $60^{\circ}$ are compared in Fig. 5(b). The model spectra, calculated using Eq. (1) and the HDT and $\mathrm{PEG}_{5}$ spectra shown in Fig. 4, predict the change in peak shape that occurs at varying beam angles. For each angle, the doted line curve is the subtraction between the experimental and the model spectra showing a relatively good matching between the two spectra. The discrepancy that can be observed around the peak A where the angular dependence is maximum probably arises from a small sample disorientation due to our experimental setup. To better show that this method is sensitive to the chemistry of the adsorbed molecules we show in Fig. 5(b) (dashed lines) the subtraction between the spectra modeled for the HDT/PEG sample and the experimental data obtained on the patterned HDT sample. One can clearly observe big discrepancies at both $\mathrm{A}$ and $\mathrm{C}$ peaks.

These results bring up a number of crucial points. First, NEXAFS offers a way to describe the surface of topographically and chemically patterned samples with dimensions as small as $150 \mathrm{~nm}$. Also, this method allows us to compare the structure and the chemistry of the molecules on the sidewalls, grooves and tops of such surfaces. We can also conclude that the average molecular orientation with respect to the surface normal remains unchanged between the sidewalls, tops, or grooves and that for each type of molecules, their density is about the same everywhere on the sample.

\section{Conclusion}

NEXAFS spectroscopy has been used in this study to characterize patterned samples with a periodic structure of a few $100 \mathrm{~nm}$. The method described here has allowed us to distinguish between different selfassembled monolayers adsorbed to the tops and sidewalls/grooves of the patterns.

\section{Acknowledgements}

This work is based upon research conducted at the Synchrotron Radiation Center, University of Wisconsin-Madison, which is supported by the NSF under Award No. DMR-0084402. The authors thank J.N. Crain and F. Himpsel for fruitful discussions.

\section{References}

Arnold, M., Cavalcanti-Adam, E.A., Glass, R., Blummel, J., Eck, W., Kantlehner, M., Kessler, H., Spatz, J.P., 2004. Activation of integrin function by nanopatterned adhesive interfaces. Chem. Phys. Chem. 5, 383-388.

Betzig, E., Trautman, J.K., 1992. Near-field optics-microscopy, spectroscopy, and surface modification beyond the diffraction limit. Science 257, 189-195.

Biebuyck, H.A., Whitesides, G.M., 1993. Interchange between monolayers on gold formed from unsymmetrical disulfides and solutions of thiols-evidence for sulfur sulfur bond-cleavage by gold metal. Langmuir 9, 1766-1770.

Britland, S., Morgan, H., Wojiak-Stodart, B., Riehle, M., Curtis, A., Wilkinson, C., 1996. Synergistic and hierarchical adhesive and topographic guidance of BHK cells. Exp. Cell Res. 228, 313325.

Cerrina, F., 1997. Application of X rays to nanolithography. Proc. IEEE 85, 644-651.

Den Braber, E.T., de Ruijter, J.E., Ginsel, L.A., von Recum, A.F., Jansen, J.A., 1998. Orientation of ECM protein deposition, fibroblast cytoskeleton, and attachment complex components on silicone microgrooved surfaces. J. Biomed. Mater. Res. 40, 291-300.

Endler, E.E., Duca, K.A., Nealey, P.F., Whitesides, G.M., Yin, J., 2003. Propagation of viruses on micropatterned host cells. Biotechnol. Bioeng. 81, 719-725.

Flemming, R.G., Murphy, C.J., Abrams, G.A., Goodman, S.L., Nealey, P.F., 1999. Effects of synthetic micro- and nanostructured surfaces on cell behavior. Biomaterials 20, 573-588.

Foley, J.D., Grunwald, E.W., Nealey, P.F., Murphy, C.J., 2005. Cooperative modulation of neuritogenesis by $\mathrm{PC} 12$ cells by topography and nerve growth factor. Biomaterials 26, 3639-3644.

Hähner, G., Kinzler, M., Thümmler, C., Wöll, C., Grunze, M., 1992. Structure of self-organizing organic films-a near edge x-ray absorption fine-structure investigation of thiol layers adsorbed on gold. J. Vac. Sci. Technol. A 10, 2758-2763.

Karuri, N.W., Liliensiek, S., Teixeira, A.I., Abrams, G., Campbell, S., Nealey, P.F., Murphy, C.J., 2004. Biological length scale topography enhances cell-substratum adhesion of human corneal epithelial cells. J. Cell Sci. 117, 3153-3164.

Khan, M., Han, G., Tsvid, G., Kitayama, T., Maldonado, J., Cerrina, F., 2001. Can proximity X-ray lithography print $35 \mathrm{~nm}$ features? Yes. J. Vac. Sci. Technol. B 19, 2423-2427.

Koo, L.Y., Irvine, D.J., Mayes, A.M., Lauffenburger, D.A., Griffith, L.G., 2002. Co-regulation of cell adhesion by nanoscale 
RGD organization and mechanical stimulus. J. Cell Sci. 115, 1423-1433.

Kumar, A., Whitesides, G.M., 1993. Features of gold having micrometer to centimeter dimensions can be formed through a combination of stamping with an elastomeric stamp and an alkanethiol ink followed by chemical etching. Appl. Phys. Lett. 63, 2002-2004.

Lopez, G.P., Albers, M.W., Schreiber, S.L., Carroll, R., Peralta, E., Whitesides, G.M., 1993. Convenient methods for patterning the adhesion of mammalian-cells to surfaces using self-assembled monolayers of alkanethiolates on gold. J. Am. Chem. Soc. 115, 5877-5878.

Mrksich, M., Chen, C.S., Xia, Y.N., Dike, L.E., Ingber, D.E., Whitesides, G.M., 1996. Controlling cell attachment on contoured surfaces with self-assembled monolayers of alkanethiolates on gold. Proc. Natl. Acad. Sci. U.S.A. 93, 10775-10778.

Pale-Grodemange, C., Simon, E.S., Prime, K.L., Whitesides, G.M., 1991. Formation of self-assembled monolayers by chemisorp- tion of derivatives of oligo(ethylene glycol) of structure $\mathrm{HS}\left(\mathrm{CH}_{2}\right) 11\left(\mathrm{OCH}_{2} \mathrm{CH}_{2}\right) \mathrm{mOH}$ on gold. J. Am. Chem. Soc. 113, 12-20.

Polak, J.M., Varndell, I.M. (Eds.), 1984. Immunolabelling for Electron Microscopy. Elsevier, New York.

Prime, K.L., Whitesides, G.M., 1991. Self-assembled organic monolayers-model systems for studying adsorption of proteins at surfaces. Science 252, 1164-1167.

Teixeira, A.I., Abrams, G.A., Bertics, P.J., Murphy, C.J., Nealey, P.F., 2003. Epithelial contact guidance on well-defined micro- and nanostructured substrates. J. Cell Sci. 116, 18811892.

Zwahlen, M., Herrwerth, S., Eck, W., Grunze, M., Hähner, G., 2003. Conformational order in oligo(ethylene glycol)-terminated self assembled monolayers on gold determined by soft X-ray absorption. Langmuir 19, 9305-9310. 